\title{
Influence of Muscle Mass, Physical Activity and Nutritional Status on Serum Creatinine and Serum Cystatin C in Elderly Population
}

\author{
Shashidhar $\mathbf{G}^{1}$, Thiagu $\mathbf{N}^{2}$, Mallikarjun ${ }^{3}$ \\ ${ }^{1}$ Professor, Department of General Medicine, ${ }^{2}$ Post Graduate, Department of General Medicine, ${ }^{3}$ Post Graduate, Department \\ of General Medicine, MVJ Medical College and Research Hospital, India
}

Corresponding author: Thiagu N, Department of General Medicine, MVJ Medical College and Research Hospital, India

DOI: http://dx.doi.org/10.21276/ijcmsr.2020.5.1.29

BY-NC-ND

How to cite this article: Shashidhar G, Thiagu N, Mallikarjun. Influence of muscle mass, physical activity and nutritional status on serum creatinine and serum cystatin $C$ in elderly population. International Journal of Contemporary Medicine Surgery and Radiology. 2020;5(1):A134-A137.

\section{A B S T R A C T}

Introduction: Decreased kidney function is common in elderly persons. Measurement of renal function is important in the diagnosis and management of renal diseases. GFR is the standard measure of renal function. It correlates with renal damage in patients with chronic kidney disease. Measurement of GFR is a complex process but easily estimated using serum creatinine and serum cystatin $C$ based formula. Aim of the study was to address the influence of muscle mass, physical activity and nutritional status on serum creatinine and serum cystatin $C$ and assess the merits of cystatin $C$ over creatinine in estimating renal function in elderly population.

Material and methods: 50 individuals aged 60-70 years attending medicine department were selected for the study. Relevant history was obtained. Anthropometric evaluation was done. Muscle mass, Nutritional status and physical activity was evaluated using body composition analyser, Mini Nutritional Assessment questionnaire, Short Physical Performance Battery protocol respectively. Blood samples were collected for estimating serum creatinine and serum cystatin C.

Results: A significant relation is found between serum creatinine and eGFR from creatinine with body weight, muscle mass, fat free mass and physical activity. Serum cystatin C and eGFR from cystatin C did not show a significant correlation with body weight, muscle mass, fat free mass and physical activity.

Conclusion: Study showed that cystatin $\mathrm{c}$ is a better reliable marker than serum creatinine in estimating renal function in elderly population.

Keywords: Serum creatinine, Serum Cystatin C, eGFR

\section{Introduction}

The proportion of elderly individuals is growing rapidly in all societies and the incidence of chronic kidney disease among elderly people increases constantly. ${ }^{1}$ The dramatic increase in prevalence of chronic kidney disease (CKD) with ageing makes the recognition of these patients of paramount relevance in order to implement interventions preventing or delaying the development of CKD complications and endstage renal disease.

Nevertheless, several issues make the diagnosis of CKD in the elderly cumbersome. Among these are age related changes in structures and functions of the kidney, which may be difficult to distinguish from CKD and multimorbidity. Thus, symptoms, clinical finding and laboratory abnormalities should be considered as potential clues to suspect $\mathrm{CKD}$ and to suggest screening. ${ }^{2}$

Measurement of renal function is important in the diagnosis and management of renal diseases. GFR is the standard measure of renal function. It correlates with renal damage in the kidneys of patients with chronic kidney disease, and it therefore reflects overall renal functional capacity. Most functions of the kidney, including endocrine ones i.e., 1,25-dihydroxyvitamin D and erythropoietin synthesis, are directly related to GFR.

In addition, appropriate dosing of drugs excreted by the kidney depends on accurate estimation of GFR. For these reasons, GFR is the most widely accepted measurement for assessing the overall function of the kidney.

Traditional methods for the determination of glomerular filtration rate (GFR) are renal or plasma clearance of suitable exogenous substances such as inulin, radiographic contrast media (e.g. iohexol) or EDTA. Although useful when high precision is necessary, clearance measurements are timeconsuming and impractical in acute situations or when a decision on drug dosing based on GFR is required at the bedside. $^{3}$

Plasma (serum) creatinine is a breakdown product of creatine and phosphocreatine found only in muscle. Despite its long tradition as a marker of GFR, does not accurately reflect renal function, especially in elderly people as it is influenced by body weight, muscle mass, nutritional status, gender, ethnicity, physical activity and in early renal impairment (the 
creatinine blind window).

Cystatin $\mathrm{C}$ is a proteinase inhibitor eliminated mainly via glomerular filtration and tubular reabsorption and degradation. It is an endogenous filtration marker produced by all nucleated cell. It is being considered as a potential replacement for serum creatinine as it is less influenced by age, sex, muscle mass and diet than creatinine. The serum concentration of cystatin $\mathrm{C}$ has been shown to be a more reliable marker for estimating renal function than serum creatinine. $^{4}$

Serum cystatin level, eGFR based on serum cystatin C concentration and comparing with serum creatinine and eGFR based on serum creatinine has not been studied extensively, but seems to be a promising method for evaluating the renal function of elderly patients.

Study aimed to address the influence of muscle mass, physical activity and nutritional status on serum creatinine and serum cystatin $\mathrm{C}$ in elderly population and to assess the merits of cystatin $\mathrm{C}$ over creatinine in estimating renal function in elderly population.

\section{MATERIAL AND METHODS}

The present study was conducted in the department of medicine, MVJ Medical College and Research Hospital, Bangalore from June 2017 to May 2019. It was a hospital based observational study. Consent was obtained from the patients participated in the study.
A total of fifty individuals aged between $60-70$ years and willing to participate in the study was included. Patients with renal disease, active rheumatological problems, taking steroids, thyroxine and creatine supplement and with congestive cardiac failure were excluded from the study.

50 individuals attending medicine department in MVJ MC \& $\mathrm{RH}$ were selected in the study as per above mentioned inclusion and exclusion criteria. Relevant history was obtained. Anthropometric evaluation was done. Muscle mass was evaluated using body composition analyser. Nutritional status was evaluated using Mini Nutritional Assessment questionnaire and people were classified as being normal, at risk of malnutrition and malnourished based on the score points obtained. Physical activity was evaluated using Short Physical Performance Battery protocol and people were classified as having very low, low, moderate and high physical activity based on the score points obtained.

Blood samples were collected for estimating serum creatinine and serum cystatin C. Serum creatinine was measured by Jaffe's calorimetric assay. Serum cystatin C was measured using nephelometry.

\section{RESULTS}

A total of fifty healthy elderly between $60-70$ years of age group were included in this study. 25 were males and 25 were females. All of them had normal urinalysis. Muscle mass was evaluated using body composition analyser. Nutritional

\begin{tabular}{|l|c|c|c|c|}
\hline Parameter & $\begin{array}{c}\text { Sedentary (very low } \\
\text { and low physical } \\
\text { activity) }\end{array}$ & $\begin{array}{c}\text { Moderate Physical } \\
\text { activity }\end{array}$ & High Physical activity & P value \\
\hline Age & $67.64 \pm 2.49$ & $67.76 \pm 2.28$ & $65.73 \pm 1.58$ & 0.017 \\
\hline Height & $152.21 \pm 6.43$ & $155 \pm 11.38$ & $163.13 \pm 8.88$ & 0.008 \\
\hline Weight & $52.5 \pm 10.1$ & $51.18 \pm 6.9$ & $66.11 \pm 9.21$ & 0.000 \\
\hline BMI & $22.79 \pm 4.6$ & $21.41 \pm 2.7$ & 24.913 .3 & 0.019 \\
\hline Muscle mass & $11.15 \pm 2.89$ & $12.36 \pm 3.6$ & $16.86 \pm 4.02$ & 0.000 \\
\hline Fat mass & $15.16 \pm 6.37$ & $11.63 \pm 3.88$ & $16.29 \pm 6.58$ & 0.037 \\
\hline Fat free mass & $37.33 \pm 6.9$ & $39.55 \pm 7.27$ & $49.82 \pm 8.62$ & 0.000 \\
\hline Serum creatinine & $0.73 \pm 0.15$ & $0.82 \pm 0.11$ & $0.9 \pm 0.15$ & 0.002 \\
\hline eGFR with creatinine & $69.5 \pm 25.93$ & $59.12 \pm 9.18$ & $72.84 \pm 12.98$ & 0.041 \\
\hline Serum cystatin C & $1.07 \pm 0.16$ & $1.08 \pm 0.09$ & $1.08 \pm 0.21$ & 0.969 \\
\hline eGFR with Cystatin-C & $75.46 \pm 14.51$ & $75.69 \pm 10.17$ & $77.97+19.06$ & 0.869 \\
\hline \multicolumn{2}{|r|}{ Table-1: Mean + standard deviations for different parameters analysed based on the physical activity } \\
\hline
\end{tabular}

\begin{tabular}{|l|c|c|c|c|}
\hline Parameter & Malnourished & At risk & Normal & P value \\
\hline Age & $66.67 \pm 2.88$ & $67.65 \pm 2.31$ & $65.3 \pm 2.31$ & 0.013 \\
\hline Height & $149 \pm 5.29$ & $156.66 \pm 10.7$ & $158.95 \pm 9.38$ & 0.348 \\
\hline Weight & $42.46 \pm 1.75$ & $54.8 \pm 9.46$ & $64.65 \pm 11.07$ & 0.002 \\
\hline BMI & $19.13 \pm 0.94$ & $22.41 \pm 3.59$ & $25.55 \pm 3.41$ & 0.011 \\
\hline Muscle mass & $9.22 \pm 1.69$ & $13.15 \pm 3.87$ & $15.44 \pm 5.04$ & 0.064 \\
\hline Fat mass & $10.18 \pm 2.35$ & $13.25 \pm 5.17$ & $17.99 \pm 7.11$ & 0.032 \\
\hline Fat free mass & $32.28 \pm 3.7$ & $41.54 \pm 8.38$ & $46.65 \pm 10.52$ & 0.044 \\
\hline Serum creatinine & $0.85 \pm 0.13$ & $0.79 \pm 0.14$ & $0.88 \pm 0.17$ & 0.210 \\
\hline eGFR with creatinine by CKD-EPI formula & $45.85 \pm 2.86$ & $66.63 \pm 17.55$ & $70.4 \pm 15.35$ & 0.090 \\
\hline Serum Cystatin C & $1.09 \pm 0.28$ & $1.07 \pm 0.12$ & $1.10 \pm 0.24$ & 0.847 \\
\hline eGFR with Cystatin C & $66.78 \pm 14.43$ & $77.03 \pm 12.82$ & $76.31+14.25$ & 0.469 \\
\hline \multicolumn{2}{|l|}{ Table-2: mean + standard deviations for different parameters analysed based on the nutritional status } \\
\hline
\end{tabular}




\begin{tabular}{|l|l|c|c|}
\hline & & $\mathbf{R}^{\mathbf{2}}$ & P Value \\
\hline Serum creatinine & Weight & 0.253 & 0.004 \\
\cline { 2 - 4 } & Muscle mass & 0.312 & 0.001 \\
\cline { 2 - 4 } & Fat free mass & 0.307 & 0.001 \\
\hline Serum Cystatin C & Weight & 0.071 & 0.329 \\
\cline { 2 - 4 } & Muscle mass & 0.003 & 0.984 \\
\cline { 2 - 4 } & Fat free mass & 0.009 & 0.934 \\
\hline \multirow{3}{*}{ eGFR creatinine } & Weight & 0.472 & 0.000 \\
\cline { 2 - 4 } & Muscle mass & 0.261 & 0.003 \\
\cline { 2 - 4 } & Fat free mass & 0.313 & 0.001 \\
\hline eGFR Cystatin C & Weight & 0.085 & 0.248 \\
\cline { 2 - 4 } & Muscle mass & 0.009 & 0.938 \\
\cline { 2 - 4 } & Fat free mass & 0.017 & 0.851 \\
\hline
\end{tabular}

Table-3: Multi variate analysis of covariance adjusted for physical activity and nutrition.

status was assessed using Mini Nutritional Assessment (MNA). Physical activity was assessed using Short Physical Performance Battery (SPPB) protocol. The correlations between muscle mass, physical activity and nutritional status with serum creatinine and cystatin $\mathrm{C}$ values were analysed using Pearson correlation coefficient.

Serum creatinine was high in people with high physical activity $(0.9 \pm 0.15 \mathrm{mg} / \mathrm{dl})$ than in people with moderate activity $(0.82 \pm 0.11 \mathrm{mg} / \mathrm{d} 1)$ and sedentary life $(0.72 \pm 0.15$ $\mathrm{mg} / \mathrm{dl})$.

This change in serum creatinine with changes in physical activity was statistically significant $(p=0.002)$. These changes can be explained by the changes in muscle mass, body weight, fat mass and fat free mass according to physical activity.

People with high physical activity had high muscle mass $(16.86 \pm 4.02 \mathrm{~kg})$ compared to those with moderate activity $(12.36 \pm 3.6 \mathrm{~kg})$ and sedentary life $(11.15 \pm 2.89 \mathrm{~kg})$. The fat free mass was high in people with high physical activity $(49.82 \pm 8.62 \mathrm{~kg})$ than those with moderate activity $(39.55 \pm$ $7.27 \mathrm{~kg})$ and sedentary life $(37.33 \pm 6.9 \mathrm{~kg})$. This change in fat free mass with physical activity is significant $(p=0.000)$. The fat mass is high in people with sedentary life $(15.16 \pm$ $6.37 \mathrm{~kg})$ compared to those with moderate activity $(11.63 \pm$ $3.88 \mathrm{~kg})$. BMI is high in people with high physical activity $\left(24.91 \pm 3.3 \mathrm{~kg} / \mathrm{m}^{2}\right)$.

Similarly, eGFR measured from serum creatinine values using CG formula was high in people with high physical activity $\left(72.84 \pm 12.98 \mathrm{ml} / \mathrm{min} / 1.73 \mathrm{~m}^{2}\right)$ than those with moderate activity $\left(5.12 \pm 9.18 \mathrm{ml} / \mathrm{min} / 1.73 \mathrm{~m}^{2}\right)$ and sedentary life $\left(69.5 \pm 25.93 \mathrm{ml} / \mathrm{min} / 1.73 \mathrm{~m}^{2}\right)$.

Serum cystatin $\mathrm{C}$ did not change with changes in physical activity. It was $1.07 \pm 0.16 \mathrm{mg} / \mathrm{L}$ in people with sedentary life, $1.08 \pm 0.09 \mathrm{mg} / \mathrm{L}$ in people with moderate activity and $1.08 \pm 0.21 \mathrm{mg} / \mathrm{L}$ in people with high physical activity. It was statistically insignificant. $(\mathrm{p}=0.969)$.

Similarly, eGFR measured from cystatin C values was nearly constant in people with high $(77.97 \pm 19.06 \mathrm{ml} / \mathrm{min} / 1.73$ $\left.\mathrm{m}^{2}\right)$, moderate $\left(75.69 \pm 10.17 \mathrm{ml} / \mathrm{min} / 1.73 \mathrm{~m}^{2}\right)$ and sedentary life $\left(75.46 \pm 14.51 \mathrm{ml} / \mathrm{min} / 1.73 \mathrm{~m}^{2}\right)$. It was statistically insignificant. $(\mathrm{p}=0.869)$.

Serum creatinine was low $(0.72 \pm 0.15 \mathrm{mg} / \mathrm{dl})$ in people with low muscle mass $(11.15 \pm 2.89 \mathrm{~kg})$ and was high $(0.9 \pm 0.15$ $\mathrm{mg} / \mathrm{dl})$ in people with high muscle mass $(16.86 \pm 4.02 \mathrm{~kg})$. It was statistically significant. $(\mathrm{p}=0.000)$.

Serum cystatin $\mathrm{C}$ did not change with changes in muscle mass. It was $(1.07 \pm 0.16 \mathrm{mg} / \mathrm{L})$ in people with low muscle mass $(11.15 \pm 2.89 \mathrm{~kg})$ and $(1.08 \pm 0.21 \mathrm{mg} / \mathrm{L})$ in people with high muscle mass $(16.86 \pm 4.02 \mathrm{~kg})$.

Serum creatinine was high in individuals $(0.88 \pm 0.17 \mathrm{mg} /$ dl) with normal nutritional status and low in individuals who were malnourished $(0.85 \pm 0.13 \mathrm{mg} / \mathrm{dl})$ with $\mathrm{P}$ value of 0.210 . Similarly, eGFR was high $(70.4 \pm 15.35 \mathrm{ml} / \mathrm{min} / 1.73 \mathrm{~m} 2)$ in people with normal nutritional status and was low (45.85 $\pm 2.86 \mathrm{ml} / \mathrm{min} / 1.73 \mathrm{~m} 2$ ) in people who were malnourished $(\mathrm{p}=0.090)$.

A significant relation was found between serum creatinine and body weight (R2=0.253), ( $\mathrm{p}=0.004)$, muscle mass $(\mathrm{R} 2=0.312), \quad(\mathrm{p}=0.001)$ and fat free mass $\left(\mathrm{R}^{2}=0.307\right)$, $(\mathrm{p}=0.001), 25.3 \%$ of variations in serum creatinine values is due to changes in body weight. $31.2 \%$ of variations in serum creatinine is due to changes in muscle mass, $30.7 \%$ of variations in serum creatinine was due to changes in fat free mass.

The estimated GFR from creatinine has significant relation with body weight $\left(\mathrm{R}^{2}=0.472\right),(\mathrm{p}=0.000)$, muscle mass $\left(\mathrm{R}^{2}=0.261\right),(\mathrm{p}=0.003)$ and fat free mass $\left(\mathrm{R}^{2}=0.313\right)$, $(p=0.001) .47 .2 \%$ of variations in eGFR from creatinine was due to changes in body weight. $26.1 \%$ of variations in eGFR from creatinine was due to changes in muscle mass. $31.3 \%$ of variations in eGFR from creatinine was due to changes in fat free mass.

\section{DISCUSSION}

Accurate detection and staging of chronic kidney disease are integral components of clinical medicine, since such evaluations have a major effect on disease labelling, drug dosages, drug interaction and risk stratification for clinical procedures.

Serum creatinine has been used as a surrogate of GFR based on the assumption that it is produced, filtered and secreted in a steady state.

The Cockcroft Gault equation was then developed to estimate creatinine clearance on the presumption that creatinine clearance was a direct measure of GFR, which is not. The reason is many factors can affect the metabolism of creatinine like creatine in the muscle, rate of secretion of creatinine in the tubules, muscle mass, gender and ethnicity, dietary protein intake, malnutrition, prescribed medications, nonlinear relationship between creatinine and GFR. All these leads to overestimation of GFR.

These limitations of creatinine led to the development of eGFR equations based on other serum biomarkers, one such biomarker is cystatin C, a protease inhibitor that is freely filtered through glomeruli, reabsorbed and degraded by the proximal tubules. Cystatin $\mathrm{C}$ levels are not affected by age, muscle mass of the individual. The use of cystatin $\mathrm{C}$ improves the role of eGFR in risk categorization, as judged by the risk of death from any cause and to a lesser extent the risks of death from cardiovascular causes and end-stage renal disease. Most notably, reduced values for cystatin C-based eGFR and eGFR based on combined measurements of creatinine and 
cystatin $\mathrm{C}$ had a consistent linear association with increased risks of death from any cause and from cardiovascular causes for all eGFR levels below approximately $85 \mathrm{ml}$ per minute per $1.73 \mathrm{~m}^{2}$, which is well above the threshold of $60 \mathrm{ml}$ per minute per $1.73 \mathrm{~m}^{2}$ for the detection of chronic kidney disease with a creatinine-based eGFR. These findings show that eGFR equations that are based on the measurement of cystatin $\mathrm{C}$ can be used to detect increased risks of adverse outcomes that are not detected with creatinine-based calculation of the eGFR. ${ }^{5}$

In our study an attempt was made to compare the influence of muscle mass, physical status and nutritional status on Serum creatinine and Cystatin $\mathrm{C}$ in elderly population.

The results are serum creatinine is high in people with high physical activity than in people with moderate activity and sedentary life and is statistically significant $(\mathrm{p}=0.002)$.

Serum creatinine is low in people with low muscle mass and is high in people with high muscle mass and is statistically significant $(\mathrm{p}=0.000)$.

Serum creatinine is high in people with normal nutritional status and low in people with malnutrition, but it is statistically insignificant $(\mathrm{p}=0.210)$.

Cystatin $\mathrm{C}$ does not change with changes in muscle mass $(p=0.984)$, physical activity $(p=0.969)$ and nutritional status $(\mathrm{p}=0.847)$. Thus, cystatin $\mathrm{C}$ is a better indicator of renal function in elderly as it is not affected by muscle mass, physical activity and nutritional status.

This is similar to the study done by Pavkov et al where serum cystatin C level is a better early predictor of progression to ESRD in persons with type 2 diabetes and elevated albuminuria than $\mathrm{mGFR}$ or serum Creatinine level, the ability of serum Cystatin C level to discriminate early on between those who progress to ESRD and those who do not progress remained superior to the other markers. ${ }^{6}$

We also attempt to compare the eGFR from the serum creatinine and serum cystatin c values.

The eGFR measured from serum creatinine using CKDEPI formula is high in individuals with high physical activity and muscle mass and low in individuals with moderate physical activity and sedentary life and low muscle mass, the difference is statistically significant with $p=0.041$ and $\mathrm{p}=0.003$ respectively.

The eGFR measured from serum cystatin $\mathrm{C}$ using CKD-EPI does not changes with muscle mass $(p=0.938)$, nutritional status $(\mathrm{p}=0.090)$ and physical activity $(\mathrm{p}=0.869)$ respectively. Thus, eGFR measured from serum cystatin $\mathrm{C}$ value is a better estimation of renal function in the elderly. This is similar to study done by Qiu X et al which shows there is a significant association of eGFR with serum Cystatin C and Serum Creatinine. Diagnostic accuracy for reduced renal function favours Serum Cystatin C. Serum Cystatin $\mathrm{C}$ was more sensitive for the estimation of GFR than Serum Creatinine when the GFR cut-off values are set as 60 (ml/ $\left.\min / 1.73 \mathrm{~m}^{2}\right){ }^{7}$

\section{Limitations of the study}

Study population is only 50 patients, measured GFR is not obtained to compare with estimated GFR, assessment of nutritional status was based on questionnaires only.

\section{CONCLUSION}

The study showed that muscle mass, nutritional status and physical activity affect the serum creatinine values and not serum cystatin values. Thus, cystatin $\mathrm{c}$ is a better reliable marker than serum creatinine in estimating renal function in elderly population.

\section{REFERENCES}

1. Flischer D. Assessment of renal function in the elderly. Current Opinion in Nephrology and Hypertension 2008; 17(1):604-08.

2. Aucella F, Corsonello A, Levosco D, Brunori G, Gesualdo L, Antonelli-Incalzi R. Beyond chronic kidney disease: the diagnosis of Renal Disease in the Elderly as an unmet need. A position paper endorsed by Italian Society of Nephrology (SIN) and Italian Society of Geriatrics and Gerontology (SIGG). Journal of Nephrology 2019;32(2):165-76

3. Garasto S, Fusco S, Corica F, Rosignuolo M, Marino A, Montesanto A et al. Estimating Glomerular Filtration Rate in Older People. BioMed Research International 2014;916542:1-12.

4. Sterner G, Bjork J, Carlson J, Grubb A, Nyman U. Validation of a new plasma cystatin C-based formula and the Modification of Diet in Renal Disease creatininebased formula for determination of glomerular filtration rate. Scandinavian Journal of Urology and Nephrology 2009; 43(5): 242-49.

5. Shlipak MG, Matsushita K, Ärnlöv J, Inker LA, Katz R, Polkinghorne KR et al. Cystatin $\mathrm{C}$ versus Creatinine in Determining Risk Based on Kidney Function. N Engl J Med 2013; 369(3):932-43.

6. Pavkov ME Knowler WC, Hanson RL, Williams DE, Lemley KV, Myers BD et al. Comparison of Serum Cystatin C, Serum Creatinine, Measured GFR, and Estimated GFR to Assess the Risk of Kidney Failure in American Indians With Diabetic Nephropathy. Am J Kidney Dis 2013;62(1):33-41.

7. Qiu X, Liu C, Ye Y, Li H, Chen Y, Fu Y et al. The diagnostic value of serum creatinine and cystatin $\mathrm{c}$ in evaluating glomerular filtration rate in patients with chronic kidney disease: a systematic literature review and meta-analysis. Oncotarget 2017;8: 72985-72999.

\section{Source of Support: Nil; Conflict of Interest: None}

Submitted: 26-11-2019; Accepted: 21-01-2020; Published online: 28-02-2020 